Article

\title{
Permeability Behavior of Nanocrystalline Solid Dispersion of Dipyridamole Generated Using NanoCrySP Technology
}

\author{
Ashish Girdhar ${ }^{\dagger}$, Poonam Singh Thakur ${ }^{\dagger}$, Sneha Sheokand and Arvind K. Bansal ${ }^{*}$ \\ Department of Pharmaceutics, National Institute of Pharmaceutical Education and Research (NIPER), Sector-67, \\ S. A. S Nagar, Mohali 160062, India; girdharashish1512@gmail.com (A.G.); \\ poonamsinghniper@gmail.com (P.S.T.); snehaniper12@gmail.com (S.S.) \\ * Correspondence: akbansal@niper.ac.in; Tel.: +91-172-2214682-2126; Fax: +91-172-2214692 \\ t These authors contributed equally.
}

Received: 1 August 2018; Accepted: 15 September 2018; Published: 17 September 2018

check for updates

\begin{abstract}
Nanocrystals research has been an area of significant interest lately, providing oral bioavailability benefits to solubility- and/or dissolution rate-limited drugs. Drug nanocrystals are generated using top-down or bottom-up technologies. Combination technologies (Nanoedge, Nanopure XP and SmartCrystal) have been recently developed to generate nanocrystals of improved properties. Our lab has also contributed in this field by providing a 'novel' platform technology, NanoCrySP, for the generation of nanocrystals. NanoCrySP-generated nanocrystals have improved the oral bioavailability of various molecules. In this study, we aim to assess the permeability behavior of nanocrystals generated by NanoCrySP. Three samples of Dipyridamole (DPM) drug were used in this study: (1) DPM (micron-sized powder), (2) nanocrystals of DPM (NS), generated by media milling (as control) and, (3) nanocrystalline solid dispersion containing DPM (NSD) in the matrix of mannitol (MAN), generated using NanoCrySP technology. In vitro (Caco-2 cell lines) and ex vivo (everted gut sac) studies were conducted in this work. Cellular permeability $\left(P_{\text {app }}\right)$ from apical-to-basolateral side in Caco-2 cell monolayer was found to be in the order NS > NSD > DPM, which was the same as their apparent solubility values. Higher $P_{\text {app }}$ from a basolateral-to-apical side suggested a significant contribution of the P-gp efflux transport for DPM, while NS exhibited much higher inhibition of the efflux mechanism than NSD. Both NS and NSD showed higher permeation from the jejunum region in the ex vivo everted gut sac study. Interestingly, $P_{\text {app }}$ of NSD was similar to NS in ex vivo everted gut sac model, however, NSD showed higher mucoadhesion than NS and DPM in this study.
\end{abstract}

Keywords: NanoCrySP; nanocrystalline solid dispersions; permeability; dipyridamole; Caco-2 cells; everted gut sac

\section{Introduction}

A crystalline form of a drug is generally preferred for formulation development over amorphous forms, due to its inherent stability. However, the crystalline form has lesser solubility than its amorphous counterpart which may compromise their oral absorption, especially for Biopharmaceutics Classification System (BCS) class II and IV drugs [1]. The oral bioavailability of such drugs can be limited by either their dissolution or solubility or both [2]. The enhancement of dissolution rate and/or solubility becomes a key factor for the formulation development of such drugs. Nanotechnology interventions such as polymeric nanoparticles, liposomes, solid lipid nanoparticles, and nanocrystals have been widely utilized for this purpose [3,4]. Amongst these approaches, drug nanocrystals have gained interest due to their high drug loading capacity, enhanced drug dissolution and scalability [5]. 
Nanocrystals can be produced using top-down or bottom-up approaches [5]. Typical top-down techniques are high-pressure homogenization and media milling. Their disadvantages include use of surfactants, long processing times, high energy input, possible contamination from the grinding media and significant downstream processing [6]. Bottom-up processes are primarily precipitation processes and suffer from disadvantages like uncontrolled crystallization and hence wide particle size distribution [7]. Our lab has developed a novel bottom-up spray-drying based technology, NanoCrySP, to produce nanocrystalline solid dispersions wherein drug nanocrystals are embedded in the matrix of a small molecule excipient [8]. Latter also encourages the nucleation of drug crystals. A solution containing drug and excipient is spray dried to obtain powder particles of size $2-50 \mu \mathrm{m}$. Each particle consists of drug crystals of size below $1000 \mathrm{~nm}$. The type and concentration of excipient, crystallization properties of the drug and spray-drying process parameters govern the formation of nanocrystals. This technology has been the subject of patents in India, US, and EU [9]. It produces nanocrystalline solid dispersion as a solid powder which can be converted to finished dosage form with minimal downstream processing. Moreover, NanoCrySP-generated nanocrystals fall under 'Class I' i.e., biodegradable in nature and size above $100 \mathrm{~nm}$, based on the Nanotoxicological Classification System [10]. This suggests negligible or low toxicity potential by nanocrystals, thus, anticipating the technology as an asset to the field. Therefore, it is imperative to study the biopharmaceutical advantages of this technique over other commercialized techniques for the generation of nanocrystals.

This study investigates the permeability behaviour of nanocrystals generated by NanoCrySP using in vitro and ex vivo tools. Dipyridamole (DPM) was selected as a model drug as it is a BCS class II compound having a $\log \mathrm{P}$ of 3.95. It is a poorly soluble weak base which displays dissolution-rate limited oral absorption, with an intrincic solubility of $8 \mu \mathrm{g} / \mathrm{mL}$ [11,12]. Additionally, it is autoflourescent in nature due to its aromatic ring system which makes it a good candidate for cell culture experiments [13]. The studies included in this work were (i) in vitro experiments using the Caco-2 cell line bidirectional transport, cellular uptake and absorption-desorption studies, and (ii) ex vivo experiments using everted gut sac (permeability and mucoadhesion studies).

\section{Materials and Methods}

\subsection{Materials}

DPM was received as a gift sample from Dr. Reddy's Laboratories (Hyderabad, India). Dioctyl sulfosuccinate sodium (DOSS), sodium lauryl sulfate (SLS), lecithin, 4-(2-Hydroxyethyl) piperazine-1-ethanesulfonic acid (HEPES), penicillin-streptomycin-amphotericin solution, ketamine, propranol, furosemide and lucifer yellow were obtained from Sigma-Aldrich (St. Louis, MO, USA). Hydroxy propyl methyl cellulose (HPMC) was purchased from Dow Chemical Company (Midland, MI, USA). Polyvinyl pyrrolidone (PVP K-30) and poloxamer were procured from BASF SE (Ludwigshafen, Germany). Ortho-phosphoric acid, dibasic potassium phosphate and D-Mannitol (MAN) were obtained from S D fine-chem Ltd. (Mumbai, India). 2-(N-Morpholino) ethanesulfonic acid hemisodium salt (MES), 3-(4,5-dimethylthiazol-2-yl)-2,5-diphenyltetrazolium bromide (MTT), phosphate buffered saline (PBS), medium 199 and sodium chloride $(\mathrm{NaCl})$ were purchased from Himedia Labs (Mumbai, Maharashtra, India). Dulbecco's modified eagle medium (DMEM), fetal bovine serum (FBS) and Hank' balanced salt solution (HBSS) were purchased from Life Technologies Pvt. Ltd. (Bengaluru, India). Non-essential amino acid (NEAA) and trypsin-EDTA solution were procured from GIBCO, Invitrogen corporation (Waltham, MA, USA). Triton-X 100 was purchased from Thermofisher scientific (Waltham, MA, USA). Caco-2 cell lines were received from National Center for Cell Science (NCCS) (Pune, India). HPLC grade methanol was obtained from Rankem Laboratories (Gurugram, India). 


\subsection{Methods}

\subsubsection{Generation of Nanocrystals of Dipyridamole (DPM)}

Nanocrystals of DPM were generated using two different processes- media milling and spray drying for NanoCrySP. Nanocrystals generated using media milling process were taken as positive control for the study. Henceforth the nanocrystals of DPM generated using media milling and spray drying process have been coded as NS and NSD, respectively.

Media milling: A total of $10 \mathrm{~mL}$ aqueous solution containing $110 \mathrm{mg}$ HPMC, $70 \mathrm{mg}$ SLS and $20 \mathrm{mg}$ DOSS was prepared in a $15 \mathrm{~mL}$ glass vial. $1000 \mathrm{mg}$ of DPM powder was then added in the aqueous solution and dispersed by vortexing for about $2 \mathrm{~min}$. The glass vial containing aqueous dispersion was charged with $5000 \mathrm{mg}$ glass beads of $150-210 \mu \mathrm{m}$ diameters and a cylindrical magnetic stirring bar of size $10 \times 6 \mathrm{~mm}$. The aqueous dispersion was then milled at a stirring speed of $1200 \mathrm{rpm}$ for $24 \mathrm{~h}$. The suspension was transferred to a glass vial, using a pipette and stored at $2-8{ }^{\circ} \mathrm{C}$ in a refrigerator until further use.

Spray drying process for NanoCrySP: $400 \mathrm{mg}$ DPM powder was dissolved in $70 \mathrm{~mL}$ of methanol and $1600 \mathrm{mg}$ MAN was dissolved in $30 \mathrm{~mL}$ of water. The aqueous phase was then slowly added to the organic phase with continuous stirring to prepare a feed solution having $2 \% w / v$ solid content. The feed solution containing DPM and MAN (1:4) was spray dried (LU228 Model, Labultima Ltd., Mumbai, India) using inlet air temperature of $90^{\circ} \mathrm{C}$, atomization pressure of $1.2 \mathrm{Kg} / \mathrm{cm}^{2}$, feed flow rate of $4 \mathrm{~mL} / \mathrm{min}$ and vacuum of $100 \mathrm{~mm}$ of water column. These conditions resulted in an outlet temperature of $45^{\circ} \mathrm{C}$. The spray dried powder was stored at $25^{\circ} \mathrm{C} / 0 \% \mathrm{RH}$ in a vacuum desiccator containing phosphorous pentoxide until further use.

\subsubsection{Differential Scanning Calorimetry (DSC)}

DSC heating curves were recorded using DSC (Q2000, TA instruments, New Castle, DE, USA) and analysed using Universal Analysis ${ }^{\circledR}$ software, version 4.5A. Samples of 2-3 mg were taken in crimped aluminium pans and subjected to a thermal scan from $25{ }^{\circ} \mathrm{C}$ to $185^{\circ} \mathrm{C}$ at a heating rate of $20{ }^{\circ} \mathrm{C} / \mathrm{min}$. A dry nitrogen purge was maintained at $50 \mathrm{~mL} / \mathrm{min}$. The instrument was calibrated using high purity standard of indium prior to analysis.

Heat-cool-heat analysis of DPM was also carried out using DSC. Sample was heated from ambient to $185^{\circ} \mathrm{C}$ at a heating rate of $20^{\circ} \mathrm{C} / \mathrm{min}$ and held isothermally for $1 \mathrm{~min}$. After this, the sample was quenched at the rate of $20^{\circ} \mathrm{C} / \mathrm{min}$ up to $0^{\circ} \mathrm{C}$. In the second heating cycle, sample was heated to $185^{\circ} \mathrm{C}$ at a heating rate of $20^{\circ} \mathrm{C} / \mathrm{min}$.

\subsubsection{Powder X-ray Diffraction (PXRD)}

X-ray diffractograms of samples were recorded at room temperature using Bruker's D8 Advance diffractometer (Mannheim, West Germany) with $\mathrm{Cu} \mathrm{K} \alpha$ radiation (1.54 $\AA$ ), at $40 \mathrm{kV}$ and $40 \mathrm{~mA}$ passing through a nickel filter. The analysis was performed in a continuous mode with a step size of $0.01^{\circ}$ and a step time of $1 \mathrm{~s}$ over an angular range of $5-40^{\circ} 2 \theta$. The diffractograms obtained were analysed with DIFFRAC plus EVA, version 9.0.

\subsubsection{Scanning Electron Microscopy (SEM)}

The surface morphology of samples was observed under a scanning electron microscope (S-3400, Hitachi Ltd., Tokyo, Japan) operated at an excitation voltage of $25 \mathrm{kV}$. A double-sided adhesive tape was used on a steel stage for sample mounting. The samples were then sputter coated with gold using ion sputter before analysis. 


\subsubsection{Dynamic Light Scattering (DLS)}

The particle size of DPM in NS and NSD was determined by the DLS technique (Zetasizer NanoZS, Malvern Instruments, Malvern, UK). Briefly, NSD (5 mg) was dispersed in a $10 \mathrm{~mL}$ of aqueous medium containing HPMC $(100 \mathrm{mg})$, SLS $(100 \mathrm{mg})$ and DOSS $(60 \mathrm{mg})$ in a $15 \mathrm{~mL}$ glass vial. The dispersion was then vortexed for $10 \mathrm{~min}$ followed by an ultrasonication (Branson 3510 ultrasonic cleaner, Marshall Scientific, Hampton, NH, USA) for 10 min and analysed. NS was diluted to a concentration of $1 \mu \mathrm{g} / \mathrm{mL}$ using deionized water and then vortexed for $2 \mathrm{~min}$ before analysis. Disposable polystyrene cuvette was used for the analysis. Three measurements (ten runs each) were performed with an equilibration time of 10 seconds. A refractive index of 1.67 was used for DPM and the analysis was carried out in backscattering mode at an angle of $173^{\circ}$. The results were reported in terms of $Z_{\text {avg }}(\mathrm{nm}), D_{90}(\mathrm{~nm})$ and PDI.

\subsubsection{Drug Content Determination}

DPM content was determined by separately dissolving $10 \mathrm{mg}$ of NSD powder and $10 \mu \mathrm{L}$ of NS in $1 \mathrm{~mL}$ of methanol. The solutions were then vortexed for $2 \mathrm{~min}$ and sonicated for $5 \mathrm{~min}$. The samples were filtered using membrane filter of pore size $0.1 \mu \mathrm{m}$ and after sufficient dilution (1/1000 times), DPM content was determined using HPLC method. The measurements were carried out in triplicate to calculate the mean and standard deviation.

\subsubsection{Solubility Study}

The apparent solubility of DPM was evaluated in HBSS buffer of $\mathrm{pH} 6.5$ adjusted with MES (referred as apical medium) and pH 7.4 adjusted with HEPES (referred as basolateral medium) and medium 199. An excess amount of DPM powder, NS or NSD powder were separately dispersed into $15 \mathrm{~mL}$ of the medium in a conical flask. The mixture was stirred in a mechanical shaking bath at $60 \mathrm{rpm}$ and $37 \pm 0.5^{\circ} \mathrm{C}$, for $120 \mathrm{~min} .1 \mathrm{~mL}$ of sample was collected at specified time intervals of 15,30 , $60,90,120 \mathrm{~min}$ and filtered through a nylon membrane syringe filter of pore size $0.1 \mu \mathrm{m} .100 \mu \mathrm{L}$ of the filtrate was then diluted with a mixture of orthophosphoric acid $(\mathrm{pH} 4.6)$ and methanol $(30 \%: 70 \% \mathrm{v} / \mathrm{v})$ to a suitable concentration and analysed using HPLC. The solubility data was expressed as an average of three measurements.

\subsubsection{HPLC Analysis of DPM}

DPM was quantified using an HPLC system consisting of Series 20AD machine (Shimadzu Corporation, Kyoto, Japan). RF-10AXL fluorescence detector (version 3.20, Kyoto, Japan) was used for the analysis of in vitro and ex vivo samples while samples from solubility studies were analysed using a photodiode array detector (SPD-10AP, Shimadzu Corporation, Kyoto, Japan). The stationary phase was Lichrosphere ${ }^{\circledR} \mathrm{C} 18(200 \times 4.6 \mathrm{~mm}, 5 \mu \mathrm{m})$ reversed-phase column and the temperature was maintained at $40{ }^{\circ} \mathrm{C}$. The mobile phase was composed of orthophosphoric acid (pH 4.6) and methanol $(30 \%: 70 \% v / v)$ run in an isocratic mode. DPM was eluted through the stationary phase at a flow rate of $1 \mathrm{~mL} / \mathrm{min}$ at a retention time of $11 \mathrm{~min}$ and detected at an excitation wavelength of $285 \mathrm{~nm}$ and an emission wavelength of $470 \mathrm{~nm}$.

HPLC method was validated for linearity, repeatability, reproducibility, and accuracy. The linearity was attained over a concentration range of $100-8000 \mathrm{ng} / \mathrm{mL}$ with a correlation coefficient of 0.999 . The repeatability and reproducibility were confirmed by coefficients of variation of less than $2 \%$.

\subsubsection{Cell Culture}

Caco-2 cell lines were obtained from NCCS, India at passage no. 49. The cells were grown in DMEM supplemented with $15 \%$ FBS, $1 \%$ penicillin-streptomycin-amphotericin solution and $1.5 \%$ NEAA solution in T-75- $\mathrm{cm}^{2}$ tissue culture flasks. The cell cultures were maintained at $37^{\circ} \mathrm{C}$ in a $\mathrm{CO}_{2}$ incubator, water jacketed with HEPA Class 100. The incubator had an atmosphere of $95 \%$ air $/ 5 \%$ 
$\mathrm{CO}_{2}$ and $95 \%$ relative humidity ( $\mathrm{RH}$ ). The cells became $80-85 \%$ confluent in $10-15$ days, estimated by observing and comparing the space occupied by the adherent cells in the flask with that of the unoccupied space under a microscope. The cells were harvested with trypsin-EDTA prior to seeding in culture plates. The Corning ${ }^{\circledR}$ costar filter inserts $\left(0.4 \mu \mathrm{m}\right.$ pore size, $\left.0.33 \mathrm{~cm}^{2}\right)$ were placed in 24-well culture plates and pre-wetted with $100 \mu \mathrm{L}$ DMEM for $2 \mathrm{~min}$. The cells, equivalent to a density of $7.5 \times 10^{4}$ cells, were pipetted out from the cell suspension and dispensed on the apical side of the filters for seeding. The basolateral side was filled with $800 \mu \mathrm{L}$ DMEM and the culture plate was kept for incubation of $6 \mathrm{~h}$. The culture medium (i.e., DMEM) was aspirated from both apical and basolateral side after $6 \mathrm{~h}$ without disturbing the cell monolayer. Fresh culture medium was added to the apical $(400 \mu \mathrm{L})$ and basolateral $(800 \mu \mathrm{L})$ side and incubated. The culture medium was changed every alternate day and the procedure was repeated for 29 days. The cells of passage number 57-70 were used for further studies.

\subsubsection{Cell Viability Studies}

The cells were harvested and seeded in three different 96-well plates at a seeding density of $1.5 \times 10^{4}$ cells per well. DPM solution was prepared in three different concentrations of 25, 500 and $1000 \mu \mathrm{g} / \mathrm{mL}$ using DMEM and methanol $(0.5 \% v / v)$. NS and NSD suspensions were prepared in concentrations equivalent to DPM solution using DMEM. The culture plates containing $200 \mu \mathrm{L}$ of solution or suspensions were incubated for 2, 24 and $48 \mathrm{~h}$. DMEM and methanol, without DPM, were taken as blank. MTT powder was dissolved in PBS to attain a final concentration of $5 \mathrm{mg} / \mathrm{mL}$. $10 \mu \mathrm{L}$ of this MTT solution was added to each well and incubated for $4 \mathrm{~h}\left(37^{\circ} \mathrm{C}, 5 \% \mathrm{CO}_{2}\right)$ to allow reduction of a yellow-coloured MTT solution to insoluble purple-coloured formazan crystals. The media was removed by aspirating using a pipette, and the formazan crystals were dissolved in $100 \mu \mathrm{L}$ of DMSO and incubated for $1 \mathrm{~h}$. Optical density was read at $570 \mathrm{~nm}$ and the background was subtracted at $630 \mathrm{~nm}$ using SpectraMax ${ }^{\circledR}$ M2/M2 UV spectrophotometer (Molecular Devices, San Jose, CL, USA). The percent cell viability was measured from Equation (1):

$$
\text { Cell viability }(\%)=\frac{\text { Signal }- \text { background }}{\text { Blank }- \text { background }} \times 100
$$

\subsubsection{In Vitro Transport Studies}

Monolayer Integrity Tests

Cell monolayer integrity was checked by (a) measuring transepithelial electrical resistance (TEER) from one side of the cell monolayer to the other side, (b) using permeability markers and, (c) measuring the amount of a non-transportable fluorescent compound, lucifer yellow, that could have leaked from the apical side to the basolateral side.

The TEER value was measured with a Millipore ERS voltameter (Millipore, Temecula, CA, USA) to evaluate the monolayer integrity. The TEER value was measured by using Equation (2):

$$
\text { TEER }=\left(R_{\text {monolayer }}-R_{\text {blank }}\right) \times A
$$

where, $R_{\text {monolayer }}$ is the resistance of the cell monolayer coupled with the filter membrane, $R_{\text {blank }}$ is the resistance of the filter membrane and $A$ is the surface area of the membrane $\left(0.33 \mathrm{~cm}^{2}\right.$ in 24 -well plates).

Propranolol $(25 \mu \mathrm{g} / \mathrm{mL})$ and furosemide $(25 \mu \mathrm{g} / \mathrm{mL})$ were utilized as high and low permeability markers, respectively, to evaluate the integrity of Caco-2 monolayer. The amounts of lucifer yellow in the apical and basolateral side were measured at the start, as well as end of the permeability study. An initial stock solution of lucifer yellow $(50 \mathrm{mM})$ was prepared in DMEM and diluted to $100 \mu \mathrm{M}$ working solution. $250 \mu \mathrm{L}$ of the working solution was added to the apical side and the basolateral side was filled with $600 \mu \mathrm{L}$ of basolateral medium. The plate was then kept in a shaker incubator at $37^{\circ} \mathrm{C}$ 
and $60 \mathrm{rpm}$ for $120 \mathrm{~min}$. After $120 \mathrm{~min}, 150 \mu \mathrm{L}$ and $300 \mu \mathrm{L}$ of the samples were withdrawn from the apical and basolateral side, respectively. The samples were analysed by fluorescence spectroscopy at an excitation wavelength of $485 \mathrm{~nm}$ and an emission wavelength of $535 \mathrm{~nm}$.

\section{Permeability Study}

The cell monolayer was washed thrice with PBS ( $\mathrm{pH}$ 7.4) to remove any traces of DMEM. The apical and basolateral compartments were filled with apical and basolateral medium, respectively, and the plate was kept for incubation for $60 \mathrm{~min}$. Suspensions of DPM, NS and NSD samples (equivalent to $25 \mu \mathrm{g} / \mathrm{mL}$ of DPM) were prepared in apical medium for apical-to-basolateral and in basolateral medium for basolateral-to-apical studies, followed by shaking and sonication for $5 \mathrm{~min}$. For apical-to-basolateral studies, $250 \mu \mathrm{L}$ of the suspensions of DPM, NS and NSD samples were separately added to the apical side and $600 \mu \mathrm{L}$ of the basolateral medium was added to the basolateral side. A sample volume of $300 \mu \mathrm{L}$ was withdrawn from the basolateral side at 15, 30, 60, 90 and $120 \mathrm{~min}$. The withdrawn volume was replaced with fresh pre-warmed $\left(37^{\circ} \mathrm{C}\right)$ basolateral medium each time.

In basolateral-to-apical studies, the suspensions of DPM, NS and NSD $(600 \mu \mathrm{L})$ were added to the basolateral side, and the $250 \mu \mathrm{L}$ of the blank apical medium was added to the apical side. Concentration in the apical side was measured by sampling $(150 \mu \mathrm{L})$ at 15, 30, 60, 90 and $120 \mathrm{~min}$. The plates with inserts were kept on an orbital shaker at $60 \mathrm{rpm}$ in the incubator and the samples were analysed by HPLC as described in Section 2.2.8. The apparent permeability coefficients, $P_{\text {app }}(\mathrm{cm} / \mathrm{s})$, for both apical-to-basolateral and basolateral-to-apical studies were calculated from Equation (3):

$$
P_{a p p}=\left[\frac{\mathrm{d} Q}{\mathrm{~d} t}\right] \times \frac{1}{A C_{0}}
$$

where $\mathrm{d} Q / \mathrm{d} t$ is the cumulative transport rate $(\mu \mathrm{g} / \mathrm{s})$ defined as the slope obtained by the linear regression of cumulative amount transported and time, $A$ is the surface area of the inserts $\left(0.33 \mathrm{~cm}^{2}\right.$ in 24-well plate), and $C_{0}$ is the initial concentration of the samples on the apical/basolateral side $(\mu \mathrm{g} / \mathrm{mL})$.

The efflux ratio (ER) was calculated from Equation (4) [14,15]:

$$
\mathrm{ER}=\frac{P_{a p p}(\text { apical }- \text { to }- \text { basolateral })}{P_{a p p}(\text { basolateral }- \text { to }- \text { apical })}
$$

\subsubsection{Cellular Uptake Studies}

The Caco- 2 cells were seeded at a density of $1.5 \times 10^{5}$ cells per well in a 24-well plate and grown to form a monolayer by incubating at $37^{\circ} \mathrm{C}$ and $95 \%$ air $/ 5 \% \mathrm{CO}_{2}$ for 15 days. DMEM was regularly changed after 2-3 days as explained in Section 2.2.9. Suspensions of DPM, NS and NSD were prepared in apical medium at concentrations equivalent to 25 and $50 \mu \mathrm{g} / \mathrm{mL}$ of DPM. The cell monolayer was incubated with suspensions of DPM, NS and NSD for $60 \mathrm{~min}$. The cells were rinsed thrice with PBS (pH 7.4) after $60 \mathrm{~min}$ incubation. Time-dependent cellular uptake (30 and $60 \mathrm{~min}$ ) of all three samples was studied qualitatively using confocal laser scanning microscope (CLSM) (Olympus Fluoview 1000, Olympus, Japan) at $405 \mathrm{~nm}$ excitation and $488 \mathrm{~nm}$ emission wavelengths.

\subsubsection{Absorption and Desorption Studies}

The cell suspension in DMEM was taken at a cell density of 75,000 cells $/ 400 \mu \mathrm{L}$. Suspensions of DPM, NS and NSD (equivalent to $25 \mu \mathrm{g} / \mathrm{mL}$ ) in DMEM were added to the cell suspension and incubated for $120 \mathrm{~min}$. The cell suspension containing samples was then centrifuged at 10,000 rpm for $15 \mathrm{~min}$ and the supernatant was removed. The pellet was washed with PBS and $1 \% w / v$ aqueous solution of Triton-X $100(100 \mu \mathrm{L})$ was added to rupture the cells. After $120 \mathrm{~min}$, methanol $(200 \mu \mathrm{L})$ was added to extract the DPM accumulated in the cells and analysed by HPLC. For desorption studies, DPM-loaded cells were centrifuged after an incubation period of $120 \mathrm{~min}$. The pellet was washed and 
re-suspended in PBS for $120 \mathrm{~min}$. The cell suspension was again centrifuged at 10,000 rpm for $15 \mathrm{~min}$ and the supernatant was withdrawn and analysed by HPLC.

\subsubsection{Ex Vivo Study using Everted Gut Sac}

Permeability Study

The study was conducted with prior permission from Institutional Animal Ethics Committee (IAEC), NIPER (Approval no. IAEC/17/14, approved on 10 January 2017). Male Sprague-Dawley rats (250-270 g) were kept on overnight fasting prior to experimentation with free access to water. The animals were anesthetized using ketamine and then sacrificed. The abdomen was opened by a midline incision and the intestine was cut into parts by keeping the duodenum segment $(10 \mathrm{~cm}$ from the stomach) and removing the jejunum $(15 \mathrm{~cm}$ after duodenum) and ileum segment $(25 \mathrm{~cm}$ from jejunum) for further use. The jejunum and ileum segments were rinsed with a solution of $0.9 \%$ $w / v \mathrm{NaCl}$. The freshly excised intestinal segments were then gently everted on glass rods to expose the mucosa on the outer side. The intestine was tied with silk thread at one end and was filled with medium 199 at $37^{\circ} \mathrm{C}$. The filled intestine was divided into sacs of approximately $4 \mathrm{~cm}$ in length, with silk thread and dissected into the pieces. Each sac was then placed in a $50 \mathrm{~mL}$ conical flask containing DPM, NS and NSD suspended in $15 \mathrm{~mL}$ pre-aerated medium 199 at $37^{\circ} \mathrm{C}$ at a concentration equivalent to $25 \mu \mathrm{g} / \mathrm{mL}$ of DPM. The sacs were incubated at $37^{\circ} \mathrm{C}$ in a shaker water bath at $60 \mathrm{rpm}$. The sacs were removed from the medium after $120 \mathrm{~min}$ and blotted dry. The sacs were cut open and the serosal fluid was collected in microcentrifuge tubes. Each sac was weighed before and after collection of the serosal fluid to accurately calculate the volume of medium present inside the sac. Length and diameter of sacs were also measured to determine the area. The experiment was performed in triplicate. The $P_{\text {app }}$ of DPM was calculated by using Equation (5):

$$
P_{\text {app }}=\left[\frac{V}{A \times T}\right] \times \frac{C_{1}}{C_{0}}
$$

where $V$ is the volume $(\mathrm{mL})$ of serosal content, $A$ is the area $\left(\mathrm{cm}^{2}\right)$ of intestinal sac, $T$ is the time (s) of incubation, $C_{0}$ is the initial concentration on mucosal side $(\mathrm{ng} / \mathrm{mL})$, while $C_{1}$ is the concentration $(\mathrm{ng} / \mathrm{mL}$ ) of the compound on serosal side after $120 \mathrm{~min}$ (or $7200 \mathrm{~s}$ ).

In addition to the permeability study, an intestinal tissue uptake study was also performed to calculate the amount of nanocrystals embedded in the tissue. The intestinal sacs, which were cut open to remove the serosal fluid (as described in the above paragraph), were homogenized in $5 \mathrm{~mL}$ PBS (pH 7.4). Methanol $(5 \mathrm{~mL})$ was added to the tissue homogenate and the mixture was again homogenized for $5 \mathrm{~min}$ followed by centrifugation at $10,000 \mathrm{rpm}$ and $4{ }^{\circ} \mathrm{C}$, for $20 \mathrm{~min}$. Acetonitrile $(10 \mathrm{~mL})$ was added to the mixture followed by shaking for $1 \mathrm{~min}$ and centrifugation at $10,000 \mathrm{rpm}$ and $4{ }^{\circ} \mathrm{C}$, for $20 \mathrm{~min} .1 \mathrm{~mL}$ of clear supernatant was pipetted out and $50 \mu \mathrm{L}$ of diazepam solution $(1 \mathrm{mg} / \mathrm{mL}$ in methanol) was added as an internal standard. The samples were kept shaking for 2 min followed by centrifugation at 15,000 rpm for $15 \mathrm{~min}$ and then analysed using HPLC method.

\section{Mucoadhesion Study}

The extent of penetration of DPM in mucosa and serosa for DPM, NS and NSD suspensions was determined using CLSM. Thin transverse sections of the gut sacs $(\sim 35 \mu \mathrm{m})$ were cut using a cryomicrotome at $-30{ }^{\circ} \mathrm{C}$ after fixing the tissue at an optimal cutting temperature and placed on a glass slide. The slides were analysed at various depth levels in the direction of $Z$-axis under a lens of $10 \times$ magnification and at an excitation wavelength of $405 \mathrm{~nm}$ and an emission wavelength of $488 \mathrm{~nm}$.

\subsubsection{Statistical Analysis}

Statistical significance of $P_{\text {app }}$ values was compared using the paired $t$-test assuming equal variances (Microsoft Excel 2007). The test was considered to be statistically significant if $p<0.05$. 


\section{Results}

\subsection{Solid-State Characterization}

Figure 1 shows the heating curves for DPM, MAN, physical mixture (PM) of DPM and MAN (1:4), NS and NSD. DPM showed a melting endotherm $\left(T_{\mathrm{m} \text { onset }}\right)$ at $163.04{ }^{\circ} \mathrm{C}(51.24 \mathrm{~J} / \mathrm{g})$ whereas MAN showed the $T_{\mathrm{m}}$ onset at $164.94{ }^{\circ} \mathrm{C}(281.50 \mathrm{~J} / \mathrm{g})$. The melting endotherm of both DPM and MAN in PM appeared at nearly the same temperature $\left(164.76^{\circ} \mathrm{C}\right)$ and hence, could not be separated out in DSC. Heat-cool-heat analysis provided the glass transition temperature $\left(T_{\mathrm{g} \text { onset }}\right)$ of DPM at $41.97^{\circ} \mathrm{C}$ $\left(0.5245 \mathrm{~J} /\left(\mathrm{g} \cdot{ }^{\circ} \mathrm{C}\right)\right)$ and crystallization temperature $\left(T_{\mathrm{c} \text { onset }}\right)$ at $133.82{ }^{\circ} \mathrm{C}(48.65 \mathrm{~J} / \mathrm{g})$ (data not shown). NS showed the $T_{\mathrm{m}}$ onset at $156.79^{\circ} \mathrm{C}(38.45 \mathrm{~J} / \mathrm{g})$ while NSD showed first melting event at $148.33{ }^{\circ} \mathrm{C}$ $(27.03 \mathrm{~J} / \mathrm{g}$ ) corresponding to $\delta$-form of MAN followed by its recrystallization and then a second melting event at $164.86^{\circ} \mathrm{C}(195.00 \mathrm{~J} / \mathrm{g})$ corresponding to overlapped melting of both DPM and $\beta$-form of MAN. Therefore, the melting event of DPM could not be confirmed by DSC. However, the PXRD patterns clearly revealed the major DPM peak at $8.1^{\circ} 2 \theta$ and other smaller DPM peaks $\left(8.8^{\circ}, 10.1^{\circ}\right.$ and $17.4^{\circ} 2 \theta$ ) in NS and NSD samples. This indicates that the obtained nanocrystals (in NS and NSD samples) consisted of crystalline DPM (Figure 2). $\beta$-form of MAN gives characteristic peaks at $10.2^{\circ}$, $14.8^{\circ}, 17.1^{\circ}, 19.1^{\circ}$ and $23.5^{\circ} 2 \theta$ values while $\delta$-form of MAN shows its characteristic peak at $9.8^{\circ}$ and absence of peaks in the region 10.0-19.0 $2 \theta$ values [16]. A mixture of polymorphic forms i.e., $\beta$ and $\delta$, of MAN was observed in case of NSD (Figure 2e) as is evident from the presence of peaks $\left(10.2^{\circ}, 14.8^{\circ}\right.$, $17.1^{\circ}, 19.1^{\circ}$ and $23.5^{\circ} 2 \theta$ ) of $\beta$-form and an intense peak at $9.8^{\circ} 2 \theta$, corresponding to $\delta$-form.

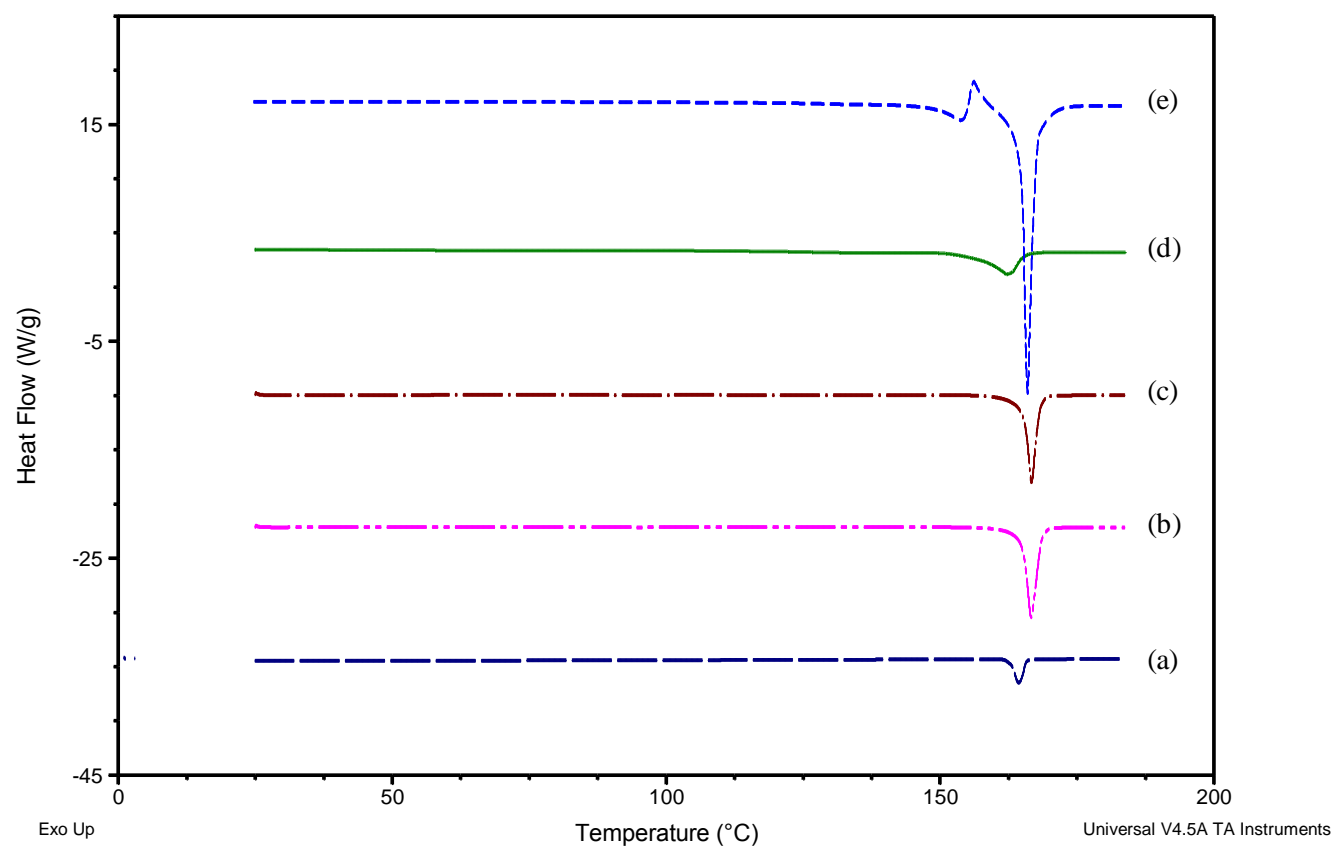

Figure 1. Differential Scanning Calorimeter (DSC) heating curves of (a) Dipyridamole (DPM) (b) Mannitol (MAN) (c) DPM-MAN physical mixture (PM) (d) Nanosuspension (NS) and (e) Nanocrystalline solid dispersion (NSD). 


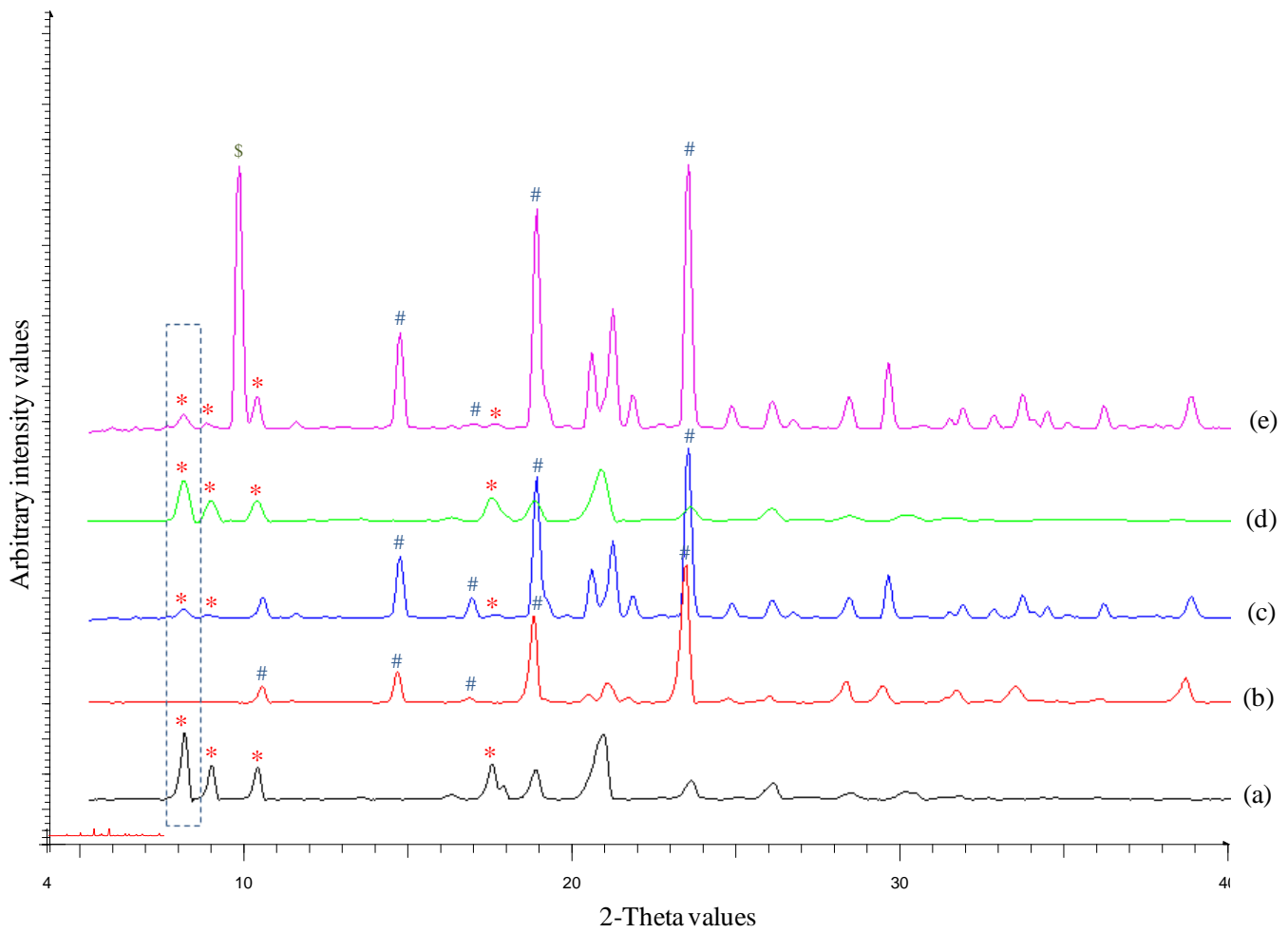

Figure 2. An overlay of X-ray diffractograms of (a) DPM (b) MAN (c) DPM-MAN PM (d) NS and (e) NSD. The characteristic peaks have been marked with symbols *, \# and \$ for DPM, $\beta$-form of MAN and $\delta$-form of MAN, respectively. The characteristic peak of DPM at $8.1^{\circ} 2 \theta$ value has been marked with a dotted box.

The $Z_{\text {avg }}$ and $D_{90}$ of DPM in NS sample were found to be $373.40( \pm 38.20) \mathrm{nm}$ and $260.30( \pm 34.90)$ $\mathrm{nm}$, respectively, with a PDI of $0.10( \pm 0.01)$. NSD showed $Z_{\text {avg }}$ of $1131.00( \pm 79.30) \mathrm{nm}$ and $D_{90}$ of $720.00( \pm 56.90) \mathrm{nm}$ with a PDI of $0.50( \pm 0.20)$. SEM images (Figure 3 ) also showed DPM particles of below $1.00 \mu \mathrm{m}$ in both NS and NSD samples. The DPM contents in NS and NSD sample were found to be $97.39( \pm 2.55) \%$ and $96.86( \pm 3.28) \%$, respectively. No significant variations $(p>0.05)$ between particle sizes of NS and NSD samples were found on storage stability testing for 30 days (data shown in Table S1).
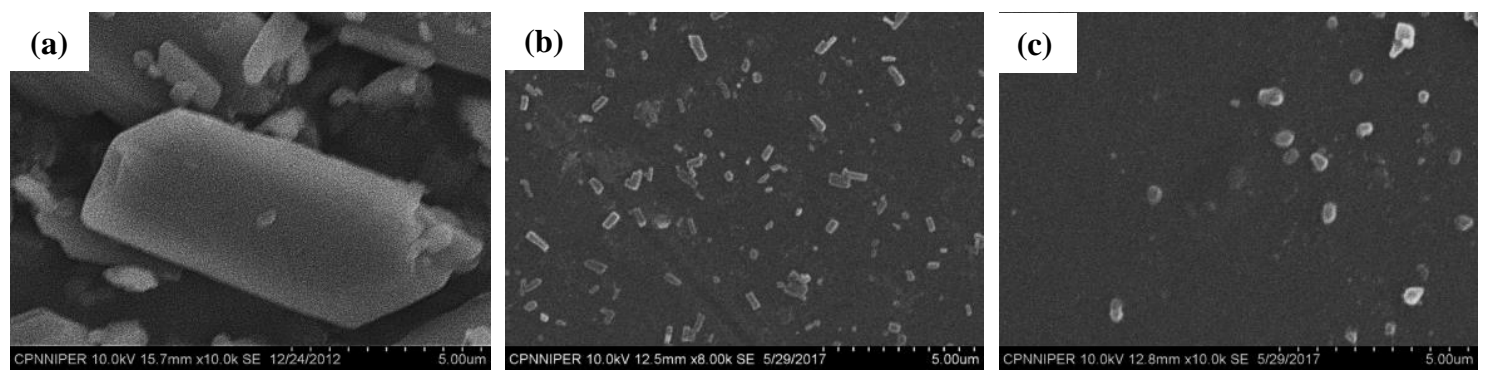

Figure 3. Scanning Electron Microscopy (SEM) photographs of (a) DPM, (b) NS and (c) NSD.

\subsection{Solubility Study}

Solubility studies of DPM, NS, and NSD were performed in three different media i.e., HBSS (pH 6.5), HBSS ( $\mathrm{pH} 7.4$ ) and medium 199. The former two media were used in in vitro studies while the latter was used in ex vivo studies. The order of solubility in all the three media was found to be NS > NSD > DPM (Table 1) at all time points (except at 15 min for medium 199). 
Table 1. The solubility of DPM in different media used during in vitro and ex vivo studies. Values are expressed in $\mu \mathrm{g} / \mathrm{mL}$ as mean \pm standard deviation.

\begin{tabular}{|c|c|c|c|c|c|c|c|c|c|}
\hline \multirow{2}{*}{ Time (min) } & \multicolumn{3}{|c|}{ HBSS pH 6.5 (Apical Medium) } & \multicolumn{3}{|c|}{ HBSS pH 7.4 (Basolateral Medium) } & \multicolumn{3}{|c|}{ Medium 199} \\
\hline & DPM & NS & NSD & DPM & NS & NSD & DPM & NS & NSD \\
\hline 15 & $4.39 \pm 0.06$ & $10.32 \pm 0.25$ & $8.78 \pm 0.33$ & $7.77 \pm 1.11$ & $23.46 \pm 1.52$ & $13.24 \pm 1.85$ & $5.05 \pm 0.11$ & $10.32 \pm 0.25$ & $10.41 \pm 0.74$ \\
\hline 30 & $8.95 \pm 0.98$ & $31.40 \pm 0.92$ & $20.83 \pm 0.95$ & $14.88 \pm 0.48$ & $46.62 \pm 2.59$ & $22.77 \pm 1.37$ & $16.62 \pm 2.44$ & $31.40 \pm 0.92$ & $24.79 \pm 1.86$ \\
\hline 60 & $24.03 \pm 1.38$ & $47.46 \pm 2.88$ & $40.74 \pm 4.03$ & $16.99 \pm 2.50$ & $57.97 \pm 0.11$ & $41.93 \pm 0.64$ & $33.65 \pm 0.71$ & $47.76 \pm 2.88$ & $44.32 \pm 2.17$ \\
\hline 90 & $36.97 \pm 1.82$ & $71.93 \pm 2.43$ & $48.50 \pm 3.79$ & $31.41 \pm 1.56$ & $70.50 \pm 1.54$ & $53.89 \pm 0.29$ & $35.71 \pm 0.15$ & $60.41 \pm 0.10$ & $50.09 \pm 0.31$ \\
\hline 120 & $52.18 \pm 0.74$ & $85.61 \pm 1.78$ & $75.21 \pm 1.40$ & $47.06 \pm 8.42$ & $79.36 \pm 2.21$ & $63.76 \pm 0.28$ & $39.53 \pm 2.57$ & $71.93 \pm 2.43$ & $59.97 \pm 0.31$ \\
\hline
\end{tabular}




\subsection{Cell Viability Studies}

The viability of Caco-2 cells was measured using the MTT test to evaluate the cytotoxicity of DPM, NS and NSD samples. MTT gives a dark purple formazan product on oxidation by mitochondrial dehydrogenase in living cells. However, mitochondrial dehydrogenase becomes inactive in damaged or dead cells. Figure 4 shows the cell viability of samples at different concentrations and incubation time intervals. Cell viability of $>80 \%$ ensured that DPM concentrations of 25,500 and $1000 \mu \mathrm{g} / \mathrm{mL}$ were non-toxic to the cells up to $2 \mathrm{~h}$. After 24 and $48 \mathrm{~h}$, a cell viability of $<60 \%$ was observed for all three concentrations of DPM. Statistical analysis of the data, using ANOVA with post-hoc Tukey's test, suggested that the variations in \% cell viability of DPM, NS and NSD were insignificant $(p>0.05)$ at all three concentrations, up to $2 \mathrm{~h}$. However, significant variations $(p<0.05)$ in $\%$ cell viability were observed in DPM vs NS and DPM vs NSD at all three concentrations up to 24 and $48 \mathrm{~h}$. NS and NSD showed no statistically significant variations $(p>0.05)$ between them up to 24 and $48 \mathrm{~h}$, with respect to the concentrations.

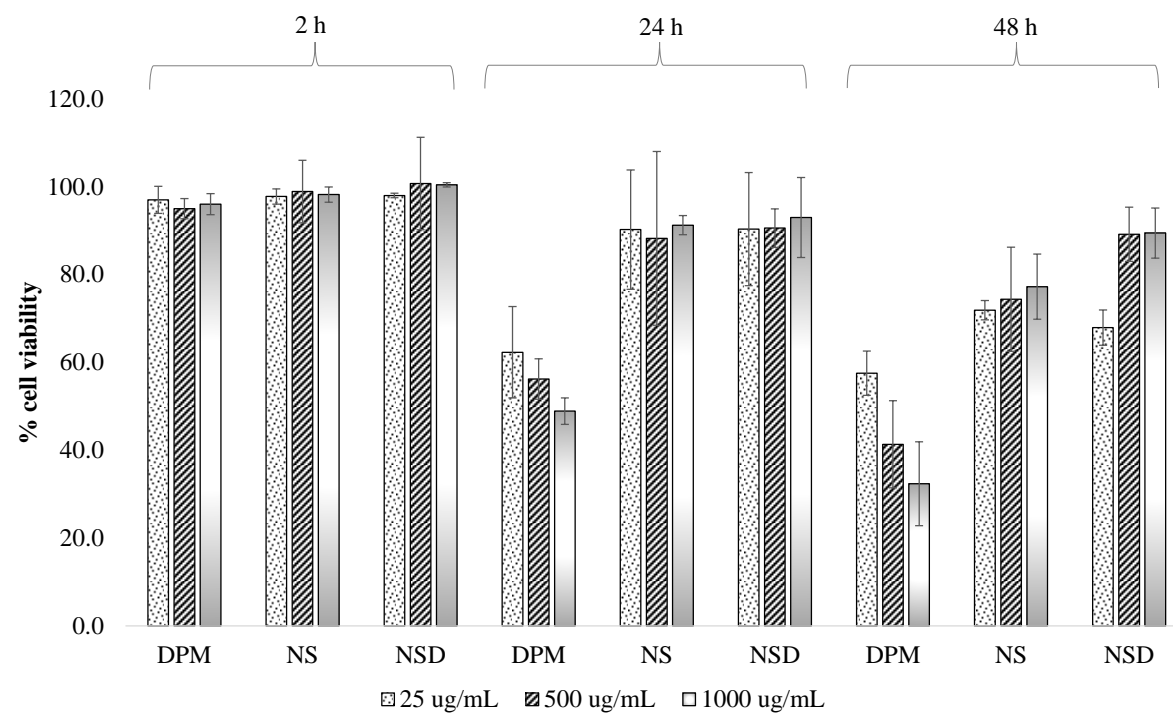

Figure 4. Cell viability (\%) of DPM, NS and NSD at different concentrations in Caco-2 cells at three incubation times $2 \mathrm{~h}, 24 \mathrm{~h}$ and $48 \mathrm{~h}$. Values are represented as a mean \pm standard deviation.

\subsection{In Vitro Transport Studies}

TEER values above $300 \mathrm{~cm}^{2}$ assured the integrity of Caco-2 cell monolayers formed with tight junctions to allow the passage of samples by transcellular route. $P_{\text {app }}$ values of the permeability markers, propranolol and furosemide, were found to be $30.40( \pm 1.23) \times 10^{-6} \mathrm{~cm} / \mathrm{s}$ and $3.21( \pm 0.27)$ $\times 10^{-6} \mathrm{~cm} / \mathrm{s}$, respectively. These $P_{\text {app }}$ values were comparable to the values reported in the literature [17-19]. $<2 \%$ permeation of lucifer yellow across the cell monolayer also complemented the TEER results. $P_{\text {app }}$ of DPM, NS and NSD samples were then determined using Caco- 2 cell monolayers. DPM showed a $P_{\text {app }}$ of $16.84( \pm 0.37) \times 10^{-6} \mathrm{~cm} / \mathrm{s}$ at $25 \mu \mathrm{g} / \mathrm{mL}$ which matched its literature reported value [20]. Table 2 shows the $P_{\text {app }}$ and ER values of all three samples from apical-to-basolateral and basolateral-to-apical. $P_{\text {app }}$ (basolateral-to-apical) of all the samples was significantly $(p<0.01)$ higher than the $P_{\text {app }}$ (apical-to-basolateral), which indicated the involvement of an efflux mechanism as reported by P-gp transporters for DPM [20]. NS showed a significant reduction in the ER of DPM by 7.8-fold while NSD showed a 4.2-fold decrease in the ER, as compared to DPM. Reduction in the efflux transport by NS and NSD samples was due to their saturation effect on the transporters [20]. 
Table 2. Bi-directional $P_{\text {app }}$ and ER data of the coarse DPM, NS, and NSD samples in Caco-2 cell monolayer. Values are represented as mean \pm standard deviation.

\begin{tabular}{cccc}
\hline Sample & $\begin{array}{c}\boldsymbol{P}_{\text {app }}(\text { Apical-to-Basolateral) } \\
\left(\mathbf{1 0}^{-\mathbf{6}} \mathbf{~} \mathbf{m} / \mathbf{s}\right)\end{array}$ & $\begin{array}{c}\boldsymbol{P}_{\text {app }} \text { (Basolateral-to-Apical) } \\
\left(\mathbf{1 0}^{-\mathbf{6}} \mathbf{~} \mathbf{m} / \mathbf{s}\right)\end{array}$ & ER \\
\hline DPM & $16.84 \pm 0.37$ & $61.01 \pm 0.51$ & $3.60 \pm 0.28$ \\
NS & $55.42 \pm 1.08$ & $25.87 \pm 0.25$ & $0.46 \pm 0.23$ \\
NSD & $33.58 \pm 0.91$ & $28.25 \pm 0.48$ & $0.84 \pm 0.35$ \\
\hline
\end{tabular}

\subsubsection{Cellular Uptake Studies}

CLSM was used to analyse the retention of DPM in Caco-2 cell monolayers in DPM, NS, and NSD after 30 and $60 \mathrm{~min}$. As can be seen in Figure 5, differences in the fluorescent intensity between DPM, NS and NSD were found at two different concentrations (25 and $50 \mu \mathrm{g} / \mathrm{mL}$ ) and two different time points (30 and $60 \mathrm{~min}$ ). Negligible uptake was observed in DPM at $25 \mu \mathrm{g} / \mathrm{mL}$ in $30 \mathrm{~min}$ and $60 \mathrm{~min}$, and showed presence of undissolved crystals at $50 \mu \mathrm{g} / \mathrm{mL}$ (refer Figure $5 \mathrm{j}$ ). The fluorescent intensity increased with time and concentration of DPM (in all 3 samples) and reached a maximum at 60 min and $50 \mu \mathrm{g} / \mathrm{mL}$, respectively. NS and NSD showed higher intensity than DPM, however, Undissolved crystals and agglomerates were observed in NSD sample at $50 \mu \mathrm{g} / \mathrm{mL}, 60 \mathrm{~min}$ (Figure 5l).
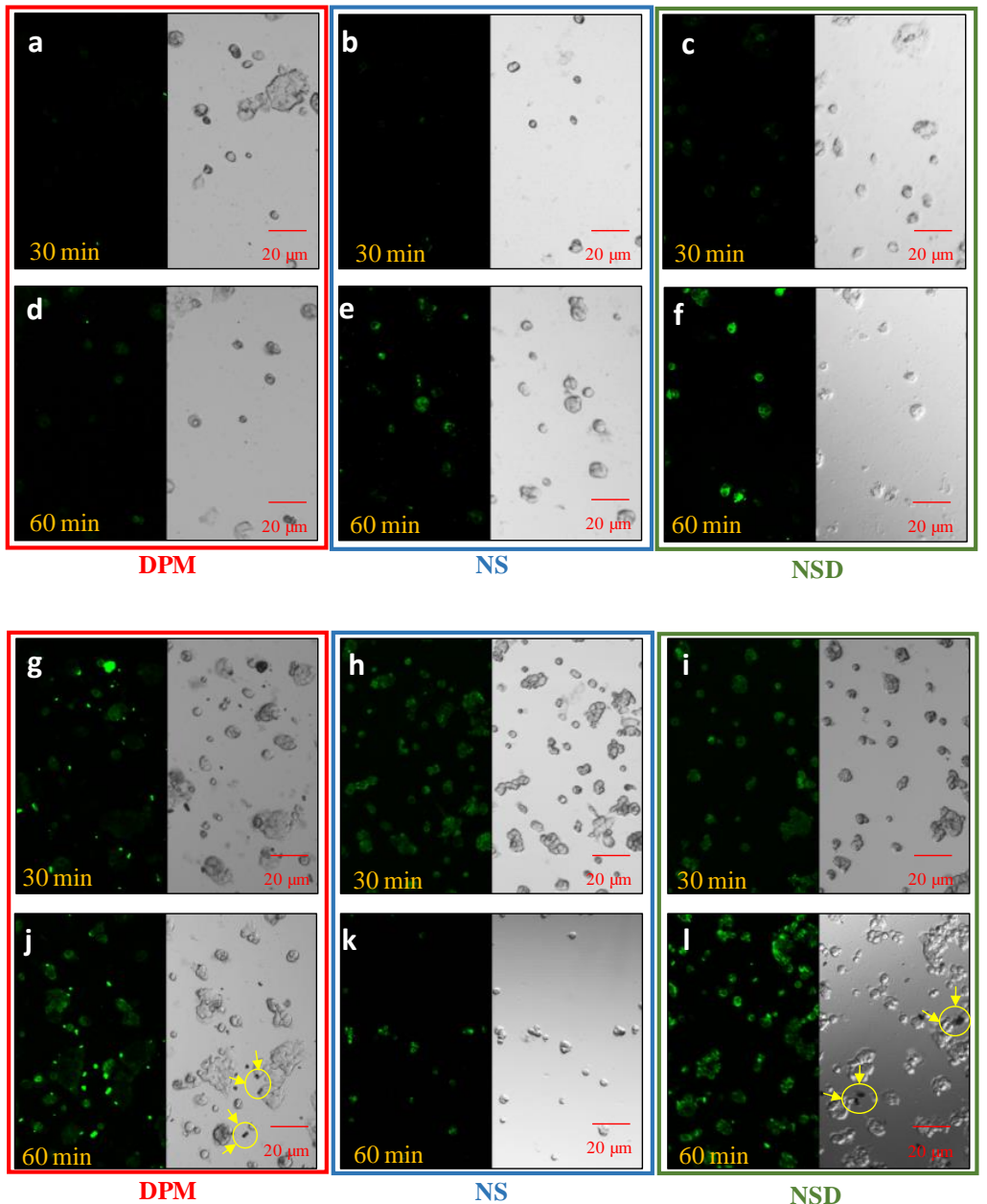

Figure 5. CLSM images of Caco-2 cells after incubation with DPM, NS, and NSD at $25 \mu \mathrm{g} / \mathrm{mL}$ (image a-f) and $50 \mu \mathrm{g} / \mathrm{mL}$ (image $\mathrm{g}-1$ ), respectively for 30 and $60 \mathrm{~min}$. Left side shows the fluorescence of DPM in the laser beam and the right side shows the phase-contrast images. Images $(\mathbf{a}, \mathbf{d}, \mathbf{g}, \mathbf{j})$ represent DPM; images $(\mathbf{b}, \mathbf{e}, \mathbf{h}, \mathbf{k})$ represent NS and; images $(\mathbf{c}, \mathbf{f}, \mathbf{i}, \mathbf{l})$ represent NSD. Encircled zones with arrows indicate particles/agglomerates observed outside the cells. 


\subsubsection{Absorption and Desorption Studies}

Absorption is the amount of DPM accumulated inside the cells while desorption is the amount coming out from the cells after suspending them in fresh PBS. Table 3 shows the percentage of DPM absorbed and desorbed from DPM, NS and NSD samples. The absorbed amount of DPM was calculated by considering the amount of initial stock solution as $100 \%$ whereas the desorbed amount was calculated by considering the absorbed amount as 100\%. The amount of DPM absorbed after an incubation of 120 min was in the order: NS > NSD > DPM. The trend for absorption was similar to that observed for $P_{\text {app }}$ (apical-to-basolateral) and solubility. The order for desorption was NS $=$ NSD $>$ DPM.

Table 3. Absorption and desorption of DPM in Caco-2 cells from DPM, NS and NSD samples. Data are expressed as the mean \pm standard deviation.

\begin{tabular}{ccc}
\hline Sample & \% DPM Absorbed & \% DPM Desorbed \\
\hline DPM & $3.55 \pm 1.56$ & $25.58 \pm 2.13$ \\
NS & $12.86 \pm 1.01$ & $55.05 \pm 3.20$ \\
NSD & $9.91 \pm 1.20$ & $51.72 \pm 2.30$ \\
\hline
\end{tabular}

\subsection{Ex Vivo Study}

\subsubsection{Permeability Study}

Table 4 shows the $P_{\text {app }}$ values for DPM, NS, and NSD sample in the everted gut sac. The permeability was determined from the jejunum and ileum segments. $P_{\text {app }}$ was higher from the jejunum segment and followed the order as NS $=$ NSD $>$ DPM where NS and NSD showed similar permeability $(p>0.05) . P_{\text {app }}$ from the ileum segment and intestinal tissue uptake of DPM in jejunal segment were followed the similar order.

Table 4. $P_{\text {app }}$ (jejunum and ileum segments) and intestinal tissue uptake (jejunal segment) values of DPM, NS, and NSD in everted gut sac. Data are expressed as the mean \pm standard deviation $(n=3)$.

\begin{tabular}{|c|c|c|c|}
\hline Sample & $\begin{array}{l}P_{\text {app }}(\text { Jejunum) } \\
\quad\left(10^{-7} \mathrm{~cm} / \mathrm{s}\right)\end{array}$ & $\begin{array}{l}P_{\text {app }}(\text { Ileum }) \\
\left(10^{-7} \mathrm{~cm} / \mathrm{s}\right)\end{array}$ & $\begin{array}{l}\text { Intestinal Tissue } \\
\text { Uptake }\left(\mathrm{ng} / \mathrm{cm}^{2}\right)\end{array}$ \\
\hline DPM & $29.64 \pm 1.42$ & $8.36 \pm 0.52$ & $336 \pm 29$ \\
\hline NS & $54.34 \pm 2.91$ & $35.34 \pm 2.51$ & $707 \pm 31$ \\
\hline NSD & $51.68 \pm 1.58$ & $40.73 \pm 2.70$ & $975 \pm 53$ \\
\hline
\end{tabular}

\subsubsection{Mucoadhesion Study}

CLSM images of a $35 \mu \mathrm{m}$ thick transverse section of the intestinal tissue, showing the fluorescent intensity in Z-plane, are as shown in Figure 6. A layer of optimum depth of intensity was selected during the Z-stacking. The fluorescent intensity of DPM, NS and NSD was measured in both serosal and mucosal sides of the intestinal tissue. The intensity was then correlated with the amount of DPM. As can be seen from Figure 6, DPM showed an intensity of 850 units in the serosal side and 1050 units in the mucosal side. Similarly, an intensity of 1500 units and 1700 units was observed for NS from the serosal and mucosal sides, respectively. NSD showed an intensity of 1700 units in the serosal side and 2600 units in the mucosal side. These intensity differences between the serosal and mucosal sides for DPM, NS and NSD samples, when compared, pointed towards the higher mucoadhesion tendency of NSD than others. In case of DPM, the large-size crystals could not adhere to the mucous and, therefore, showed no significant intensity difference between mucosal and serosal side.

In order to further confirm the mucoadhesion of nanocrystals in the intestinal tissue, longitudinal sections of the jejunum segment (treated with NSD) were observed in CLSM. As shown in Figure 7, clear differences in the fluorescence pattern were observed in mucosal and serosal sides. Tiny particles/crystals of NSD, embedded on the mucosal side of the intestinal segment, could be 
observed. Therefore, NSD sample showed higher mucoadhesion than NS and DPM as was evident from the microscopic analysis (in Figure 6).

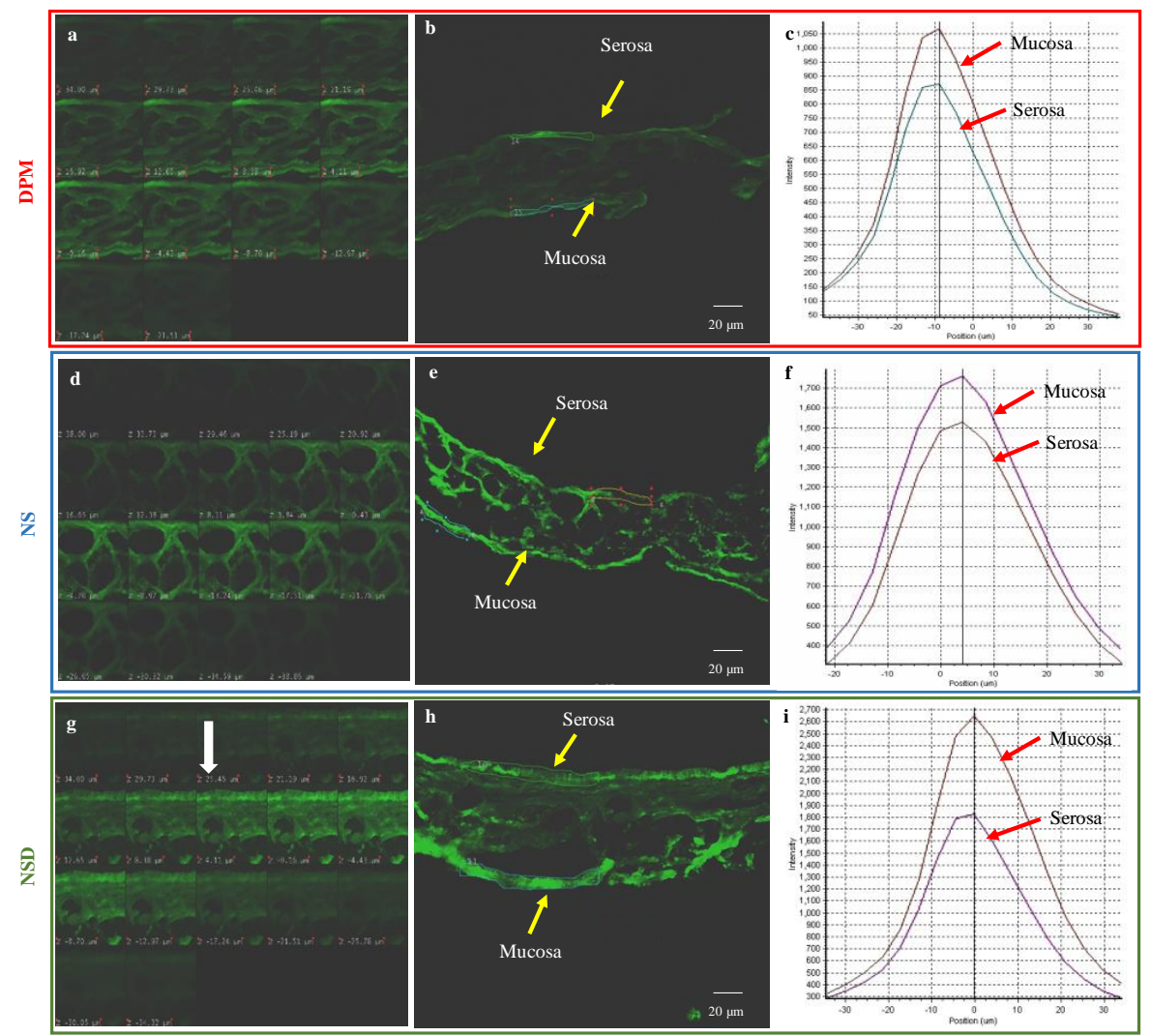

Figure 6. CLSM images of a transverse section of the jejunum segment of the everted gut sac. Images $(\mathbf{a}-\mathbf{c})$ represen DPM, images $(\mathbf{d}-\mathbf{f})$ represent NS and images $(\mathbf{g}-\mathbf{i})$ represent NSD. Images $(\mathbf{a}, \mathbf{d}, \mathbf{g})$ depict the Z-stack of the sac in increasing depth. Images $(\mathbf{b}, \mathbf{e})$, and h represent the selected images of optimal intensity. Images $(\mathbf{c}, \mathbf{f}, \mathbf{i})$ represent the measured intensity at serosal and mucosal side.

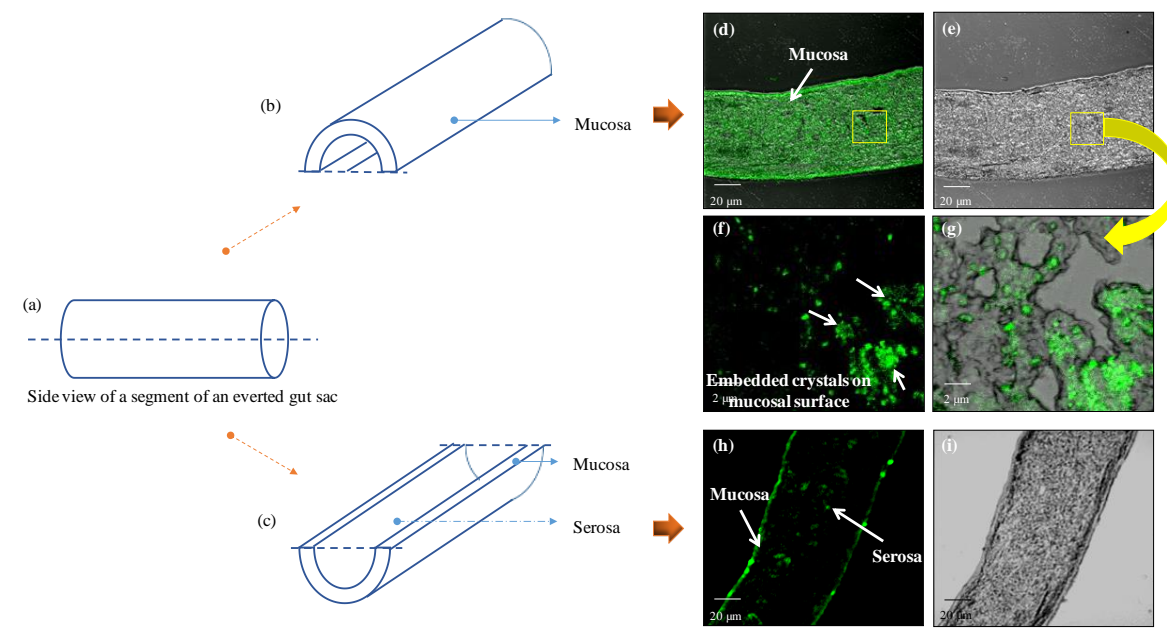

Figure 7. Schematic representation of the mucosal and serosal side on everted gut sac: (a) Side view of the jejunum segment of the everted gut sac; $(\mathbf{b}, \mathbf{c})$ depict the mucosal and serosal side of the gut sac after sectioning (longitudinal). CLSM images ( $\mathbf{d}-\mathbf{i})$ of NSD treated gut represent: (d) phase contrast and (e) bright field of the mucosal side. Images $(\mathbf{f}, \mathbf{g})$ represent a zoomed in picture of the images $(\mathbf{d}, \mathbf{e})$ which show the presence of crystals embedded on the mucosal surface. Images $(\mathbf{h}, \mathbf{i})$ represent the phase contrast and bright field of the serosal side of the gut. 


\section{Discussion}

According to the Noyes-Whitney equation [21], nanocrystals are well known to increase the dissolution rate of a drug due to decrease in particle size and corresponding increase in the surface area of the drug particles. Besides dissolution rate, particle size reduction has effect on the apparent solubility of the drug and according to Ostwald-Freundlich equation, the apparent solubility increases significantly on reducing particle size below $1000 \mathrm{~nm}$ [5]. This is because the reduction of size below $1000 \mathrm{~nm}$ increases solvation pressure, fostering an increase in the solubility and also causing disruption of solute-solute interaction which eases the solubilization process [5,22]. Permeability has been reported to be modulated by (a) concentration gradient (b) particle size of the formulation (c) alteration of cell membrane integrity and $(d)$ inhibition of efflux transporters [23-25]. In the next few sections, we will discuss the potential reasons for increase in the permeability of DPM in nanocrystals in comparison to their micronized counterpart.

The sequence of $P_{\text {app }}$ through Caco-2 cells (apical-to-basolateral) was NS > NSD > DPM, and NS = NSD $>$ DPM through everted gut sac (mucosa-to-serosa). The samples for permeability studies were suspensions containing different solubilised portions of DPM. The solubilized portion for DPM, NS and NSD were $5.10( \pm 0.90), 6.32( \pm 0.82)$ and $6.07( \pm 1.20) \mu \mathrm{g} / \mathrm{mL}$, respectively, in HBSS (pH 6.5). The time-dependent solubility data in this medium is shown in Table 1 . It is evident that the 'difference in solubility' increased in a time-dependent manner. The solubility difference for NS and NSD w.r.t. DPM was 1.64- and 1.44-fold, respectively. Possibly, the 'difference in permeability' were contributed by the concentration-gradient due to increased solubilisation as well as dissolution efficiency. These two simultaneously occurring phenomenon took place more efficiently in case of NS as it provided discrete particles suspended in the medium against agglomerates seen in NSD (Figure 5j,1). $P_{\text {app }}$ (basolateral-to-apical) was also evaluated in Caco-2 cells wherein the sequence observed was DPM > NSD > NS. The possible reason for this could be saturation of the transport system because the concentration-dependent inhibition of the P-gp efflux has already been reported for DPM in the literature [20].

Nanocrystals have been reported to be internalized by the cells in a size-dependent manner. Previous reports have indicated efficient internalization of particles less than $200 \mathrm{~nm}$ [24]. The results of cell internalization (or absorption-desorption) studies established increased internalization in case of NS than NSD. Though the initial particle sizes $\left(D_{90}\right)$ for NS and NSD were $260.3( \pm 34.9) \mathrm{nm}$ and $720.0( \pm 56.9) \mathrm{nm}$, solubilisation in the buffer medium could have decreased the size of the crystals in a time-dependent manner (as discussed in the above paragraph). This would have contributed to cellular internalization over a period of time. It is also reported that presence of surfactants contributes to enhanced internalization due to its impact on the biochemistry of the cell membrane [26,27]. Therefore, NS showed enhanced internalization due to the presence of SLS and DOSS which were absent in case of NSD and DPM. The internalized nanocrystals subsequently dissolve in the cellular matrix [28] and permeate to the donor compartment.

A similar trend in solubility as that observed in Caco-2 cell studies was observed in the everted gut sac experiments. The solubility difference for NS and NSD w.r.t. DPM was 1.82- and 1.52-fold, respectively. However, it was interesting to note that despite 'difference in solubility', both NS and NSD showed similar permeability. This was further investigated by conducting the mucoadhesion study as nanocrystals have been reported to possess enhanced mucoadhesion besides solubility enhancement and internalization. Everted gut sac of a rat represents the intestinal tissue with mucous as well as a serosal layer. NSD was found to show the highest mucoadhesion followed by NS and DPM (Figures 6 and 7). The adhered particles are expected to dissolve and permeate over a period of time.

Table 5 captures various contributors to the experimental differences in the permeability behaviour. $P_{\text {app }}$ (apical-to-basolateral), $P_{\text {app }}$ (basolateral-to-apical), solubility, and internalization were better for NS, while mucoadhesion was better in case of NSD. 
Table 5. Comparison of performance of DPM, NS and NSD w.r.t. various contributors studied in the present work.

\begin{tabular}{cccc}
\hline Contributors & DPM & NS & NSD \\
\hline Solubility (in HBSS pH 6.5 after 120 min) & 1.00 & 1.64 & 1.44 \\
Solubility (in medium 199 after 120 min) & 1.00 & 1.82 & 1.52 \\
$P_{\text {app (apical-to-basolateral) }}$ & 1.00 & 3.30 & 2.35 \\
$P_{\text {app }}$ (basolateral-to-apical) & 1.00 & 0.54 & 0.87 \\
$P_{\text {app }}$ (mucosa-to-serosa) & 1.00 & 1.83 & 1.74 \\
Mucoadhesion & 1.00 & 3.62 & 2.79 \\
Internalization (absorption-desorption study) & 1.00 & 1.42 & 2.47
\end{tabular}

* Contribution of DPM has been assumed to be 1 for comparison of the performance of NS and NSD in various aspects.

Nanocrystals represent an attractive approach for an increasing number of poorly water-soluble compounds in the product pipeline. Despite the benefits of increased apparent solubility, dissolution rate and permeability, the nanocrystal technology has some limitations. Physical instability of nanosuspensions, which includes sedimentation, crystal growth (also known as Ostwald ripening), aggregation and solid-state transformation, pose challenge in the top-down approach. Another well-known issue with the nanosuspensions is the possible degradation of drugs during generation of nanocrystals (such as due to milling-induced stresses). One of the main advantages of nanocrystalline solid dispersions over nanosuspensions is their physical stability. The final product is obtained as a solid powder and hence, more stable than nanosuspensions. Therefore, exploring nanocrystalline solid dispersions as an alternative to the nanosuspensions, without compromising the desired performance, is an area of work for future work.

\section{Conclusions}

Two nanocrystal-based formulations, i.e., nanosuspension and NanoCrySP-generated nanocrystalline solid dispersion, were compared for their permeability behaviour, cellular internalization, and mucoadhesion. The interplay of concentration-gradient created by the solubility values and mucoadhesion imparted their permeability behaviour. Everted gut sac experiments enabled an understanding of the role of mucoadhesion in the overall permeability behaviour. Though the particle size obtained in the NanoCrySP-based formulation was higher than the nanosuspension, the permeability of the former was comparable to the latter. This work establishes that, besides solubility differences and cellular internalization, mucoadhesion is one of the major contributors to overall permeability in GIT. Mucoadhesion can maintain the local supersaturation and concentration flux by embedded crystals on the mucosa to facilitate absorption. This makes the nanocrystalline solid dispersions an affordable and quality formulation for the industry.

Supplementary Materials: The following are available online at http:/ / www.mdpi.com/1999-4923/10/3/160/s1, Table S1: Particle size analysis for stability evaluation of NS and NSD for 30 days.

Author Contributions: Conceptualization, P.S.T. and S.S.; Formal analysis, A.G. and P.S.T.; Methodology, A.G. and P.S.T.; Project administration, A.K.B.; Supervision, A.K.B.; Writing: original draft, S.S.; Writing: review and editing, S.S.

Funding: This research received no external funding.

Acknowledgments: Authors would like to acknowledge Sanjay Kumar Samal and Mahesh Kashyap (Department of Pharmaceutics, NIPER, SAS Nagar) for their support in in vitro and CLSM experiments, respectively. Poonam Singh Thakur acknowledges Science and Engineering Research Board (SERB), Department of Science and Technology (DST), Government of India for Junior Research Fellowship. Sneha Sheokand acknowledges Department of Biotechnology (DBT), Government of India for Junior Research Fellowship.

Conflicts of Interest: On behalf of all authors, the corresponding author states that there is no conflict of interest. 


\section{References}

1. Kaushal, A.M.; Gupta, P.; Bansal, A.K. Amorphous drug delivery systems: Molecular aspects, design, and performance. Crit. Rev. Ther. Drug Carrier Syst. 2004, 21, 133-193. [CrossRef] [PubMed]

2. Yu, L. An integrated absorption model for determining dissolution, permeability, and solubility limited absorption. Pharm. Res. 1999, 16, 1884-1888.

3. Riehemann, K.; Schneider, S.W.; Luger, T.A.; Godin, B.; Ferrari, M.; Fuchs, H. Nanomedicine-challenge and perspectives. Angew. Chem. Int. Ed. 2009, 48, 872-897. [CrossRef] [PubMed]

4. Bamrungsap, S.; Zhao, Z.; Chen, T.; Wang, L.; Li, C.; Fu, T.; Tan, W. Nanotechnology in therapeutics: A focus on nanoparticles as a drug delivery system. Nanomedicine 2012, 7, 1253-1271. [CrossRef] [PubMed]

5. Junghanns, J.-U.A.; Müller, R.H. Nanocrystal technology, drug delivery and clinical applications. Int. J. Nanomed. 2008, 3, 295-310.

6. George, M.; Ghosh, I. Identifying the correlation between drug/stabilizer properties and critical quality attributes (CQAs) of nanosuspension formulation prepared by wet media milling technology. Eur. J. Pharm. Sci. 2013, 48, 142-152. [CrossRef] [PubMed]

7. Khan, S.; Matas, M.D.; Zhang, J.; Anwar, J. Nanocrystal preparation: Low-energy precipitation method revisited. Cryst. Growth Des. 2013, 13, 2766-2777. [CrossRef]

8. Shete, G.; Bansal, A.K. NanoCrySP technology for generation of drug nanocrystals: Translational aspects and business potential. Drug Deliv. Trans. Res. 2016, 6, 392-398. [CrossRef] [PubMed]

9. Bansal, A.K.; Dantuluri, A.K.R.; Bhaskarao, S.G.; Bapurao, P.Y. Nanocrystalline Solid Dispersion Compositions and Process of Preparation Thereof. WO2013132457A2. 7 March 2012.

10. Keck, C.M.; Müller, R.H. Nanotoxicological classification system (NCS)—A guide for the risk-benefit assessment of nanoparticulate drug delivery systems. Eur. J. Pharm. Biopharm. 2013, 84, 445-448. [CrossRef] [PubMed]

11. He, X.; Kadomura, S.; Takekuma, Y.; Sugawara, M.; Miyazaki, K. A new system for the prediction of drug absorption using a pH-controlled Caco-2 model: Evaluation of $\mathrm{pH}$-dependent soluble drug absorption and pH-related changes in absorption. J. Pham. Sci. 2004, 93, 71-77. [CrossRef] [PubMed]

12. Kostewicz, E.S.; Brauns, U.; Becker, R.; Dressman, J.B. Forecasting the oral absorption behavior of poorly soluble weak bases using solubility and dissolution studies in biorelevant media. Pharm. Res. 2002, 19, 345-349. [CrossRef] [PubMed]

13. Iuliano, L.; Piccheri, C.; Coppola, I.; Pratico, D.; Micheletta, F.; Violi, F. Fluorescence quenching of dipyridamole associated to peroxyl radical scavenging: A versatile probe to measure the chain breaking antioxidant activity of biomolecules. Biochim. Biophys. Acta 2000, 1474, 177-182. [CrossRef]

14. Bagul, P.; Khomane, K.S.; Bansal, A.K. Investigating permeability related hurdles in oral delivery of 11-keto- $\beta$-boswellic acid. Int. J. Pharm. 2014, 464, 104-110. [CrossRef] [PubMed]

15. Wahlang, B.; Pawar, Y.B.; Bansal, A.K. Identification of permeability-related hurdles in oral delivery of curcumin using the Caco-2 cell model. Eur. J. Pharm. Biopharm. 2011, 77, 275-282. [CrossRef] [PubMed]

16. Cares-Pacheco, M.; Vaca-Medina, G.; Calvet, R.; Espitalier, F.; Letourneau, J.-J.; Rouilly, A.; Rodier, E. Physicochemical characterization of D-mannitol polymorphs: The challenging surface energy determination by inverse gas chromatography in the infinite dilution region. Int. J. Pharm. 2014, 475, 69-81. [CrossRef] [PubMed]

17. Artursson, P.; Karlsson, J. Correlation between oral drug absorption in humans and apparent drug permeability coefficients in human intestinal epithelial (Caco-2) cells. Biochem. Biophys. Res. Commun. 1991, 175, 880-885. [CrossRef]

18. Hidalgo, I.J.; Raub, T.J.; Borchardt, R.T. Characterization of the human colon carcinoma cell line (Caco-2) as a model system for intestinal epithelial permeability. Gastroenterology 1989, 96, 736-749. [CrossRef]

19. Yee, S. In vitro permeability across Caco-2 cells (colonic) can predict in vivo (small intestinal) absorption in man-fact or myth. Pharm. Res. 1997, 14, 763-766. [CrossRef] [PubMed]

20. Elsby, R.; Surry, D.; Smith, V.; Gray, A. Validation and application of Caco-2 assays for the in vitro evaluation of development candidate drugs as substrates or inhibitors of P-glycoprotein to support regulatory submissions. Xenobiotica 2008, 38, 1140-1164. [CrossRef] [PubMed]

21. Dokoumetzidis, A.; Macheras, P. A century of dissolution research: From Noyes and Whitney to the biopharmaceutics classification system. Int. J. Pharm. 2006, 321,1-11. [CrossRef] [PubMed] 
22. Williams, H.D.; Trevaskis, N.L.; Charman, S.A.; Shanker, R.M.; Charman, W.N.; Pouton, C.W.; Porter, C.J. Strategies to address low drug solubility in discovery and development. Pharmacol. Rev. 2013, 65, 315-499. [CrossRef] [PubMed]

23. Müller, R.H.; Gohla, S.; Keck, C.M. State of the art of nanocrystals-special features, production, nanotoxicology aspects and intracellular delivery. Eur. J. Pharm. Biopharm. 2011, 78, 1-9. [CrossRef] [PubMed]

24. Chen, Y.; Li, T. Cellular uptake mechanism of paclitaxel nanocrystals determined by confocal imaging and kinetic measurement. AAPS J. 2015, 17, 1126-1134. [CrossRef] [PubMed]

25. Swenson, E.S.; Curatolo, W.J. (C) Means to enhance penetration: (2) Intestinal permeability enhancement for proteins, peptides and other polar drugs: Mechanisms and potential toxicity. Adv. Drug Deliv. Rev. 1992, 8, 39-92. [CrossRef]

26. Dimitrijevic, D.; Shaw, A.J.; Florence, A.T. Effects of some non-ionic surfactants on transepithelial permeability in Caco-2 cells. J. Pharm. Pharmacol. 2000, 52, 157-162. [CrossRef] [PubMed]

27. Boulenc, X.; Breul, T.; Gautier, J.-C.; Saudemon, P.; Joyeux, H.; Roques, C.; Berger, Y.; Fabre, G. Sodium lauryl sulphate increases tiludronate paracellular transport using human epithelial caco-2 monolayers. Int. J. Pharm. 1995, 123, 71-83. [CrossRef]

28. Peltonen, L.; Strachan, C. Understanding critical quality attributes for nanocrystals from preparation to delivery. Molecules 2015, 20, 22286-22300. [CrossRef] [PubMed]

(C) 2018 by the authors. Licensee MDPI, Basel, Switzerland. This article is an open access article distributed under the terms and conditions of the Creative Commons Attribution (CC BY) license (http://creativecommons.org/licenses/by/4.0/). 